\title{
A- and B-modes echobiometry in cataractous and noncataractous eyes of English Cocker Spaniel dogs
}

[Ecobiometria nos modos A e B, de olhos de cães da raça Cocker Spaniel Inglês com e sem catarata]

\author{
M.L. Silva ${ }^{1}$, B.C. Martins ${ }^{1}$, A.P. Ribeiro ${ }^{1}$, A.L. Groszewicz de Souza ${ }^{1}$, J.L. Laus $^{2 *}$ \\ ${ }^{1}$ Aluno de pós-graduação - FCAV-UNESP - Jaboticabal, SP \\ ${ }^{2}$ Faculdade de Ciências Agrárias e Veterinárias - UNESP - Jaboticabal \\ Via de Acesso Prof. Paulo Donato Castellane, s/n \\ 14884-900 - Jaboticabal, SP
}

\begin{abstract}
A- and B-modes ultrasonographic changes in the thickness of various structures of the eyeball in male and female English Cocker Spaniel dogs with and without nondiabetic cataracts were evaluated. Sixteen dogs with cataracts (32 eyes) and seven normal dogs (14 eyes) older than eight years were selected. Aand B-modes ultrasonography was performed with a $10 \mathrm{MHz}$ transducer. Data was statistically evaluated by one way ANOVA. Mean and standard deviations of various ocular structures for dogs with and without cataracts were, respectively, anterior chamber: $3.041 \pm 0.828 \mathrm{~mm}, 3.373 \pm 1.040 \mathrm{~mm}$; lens: $6.817 \pm 1.117 \mathrm{~mm}, 7.062 \pm 0.477 \mathrm{~mm}$; vitreous: $10.056 \pm 0.754 \mathrm{~mm}, 9.523 \pm 0.705 \mathrm{~mm}$; and axial length: $19.909 \pm 1.103 \mathrm{~mm}, 19.958 \pm 1.050 \mathrm{~mm}$. Ocular measurements between right and left eyes, males and females, as well as in eyes with and without cataract were not different $(\mathrm{P}>0.05)$.
\end{abstract}

Keywords: dog, ultrasonography, cataract

\section{RESUMO}

Avaliaram-se as alterações na dimensão de estruturas do bulbo do olho de cães da raça Cocker Spaniel Inglês, machos e fêmeas, com ou sem catarata não diabética. Dezesseis animais com catarata $(n=32$ olhos) com idade acima de oito anos e um grupo-controle, composto por sete cães, com idades também acima de oito anos, sem catarata $(n=14$ olhos) compuseram a pesquisa. Realizou-se ultrassonografia transcorneana nos modos A e B com transdutor de 10MHz. Os dados foram submetidos à análise de variância e ao teste Tukey para comparação de médias. O comprimento axial do bulbo do olho dos animais com catarata e dos animais do grupo-controle foram, respectivamente, 19,909 $\pm 1,103 \mathrm{~mm} e$

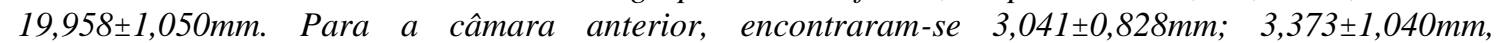

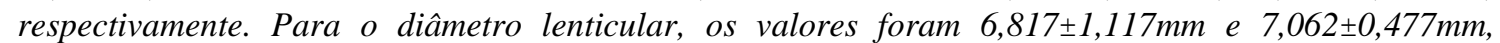
respectivamente, e para o segmento posterior, 10,056 $\pm 0,754 \mathrm{~mm}$ e 9,523 $\pm 0,705 \mathrm{~mm}$, respectivamente. Não se encontraram diferenças significativas entre olhos com catarata e do grupo-controle, tampouco entre machos e fêmeas com e sem catarata, nem entre olhos direitos e esquerdos $(P>0,05)$.

Palavras-chave: cão, ultrassonografia, catarata

\section{INTRODUCTION}

The English Cocker Spaniel comes from the Epagneul dog which was introduced in Great Britain in the fourteenth century as a hunting breed. Through the centuries, it became cosmopolitan, being one of the most common breeds to develop ocular diseases (Davidson and Nelms, 1999).

The eye problems frequently manifested by the English Cocker Spaniel include congenital and

Recebido em 20 de abril de 2009

Aceito em 10 de agosto de 2010

*Autor para correspondência (corresponding author)

E-mail: jllaus@fcav.unesp.br 
non congenital cataracts, closed angle glaucoma, progressive retinal atrophy, retinal dysplasia, and keratoconjunctivitis sicca (Petersen-Jones, 1999). In North America, the English Cocker Spaniel is one of the eight breeds with the highest cataract prevalence (8.2\%) (Gelatt and Mackay, 2005).

In dogs, ocular ultrasonography was first used in 1968 (Davidson and Nelms, 1999). Echobiometric comparisons of the ocular segments between dolicocephalic and brachiocephalic breeds showed differences regarding the axial globe length (Cottrill et al., 1989).

Tuntivanich et al. (2007) showed by means of Bmode ultrasonography that the axial globe length rapidly increases up to 52 weeks of age, after which little change occurs until adulthood. Ekesten et al. (1995) found similar results in the axial globe length when the A-mode was used. However, in the A-mode technique, differences in the anterior and vitreous chambers measurements were found in unsedated dogs, compared to the sedated ones (Ekesten et al., 1995).

Considering that mature and diffuse cataract do not allow a useful visualization of the posterior segment of the eye, ultrasonography is a valuable tool to evaluate vitreous and retinal conditions, as well as the stage of cataracts (van der Woerdt et al., 1993; Brazitikos et al., 1999). Williams (2004) employed B-mode ultrasonography to compare normal and cataractous lens in dogs. Lenses with diabetic cataracts were significantly increased in axial thickness compared to lenses in other eyes, although lenses with mature cataracts showed a trend towards increased axial thickness and immature cataracts demonstrated a trend towards reduced thickness (Martins et al., 2010). van der Woerdt et al. (1993) found changes in the refractive media, notably vitreous degeneration and retinal detachment in eyes examined by ultrasonography.

Two modes are considered feasible: the linear or A-scan mode and the B-scan mode. The A-scan echogram generates peaks or spikes of different heights from the isoeletric baseline which are formed by different densities of the ocular tissues. The B-scan mode, however, allows a two-dimensional real-time image of the eye and orbit (Gonzalez et al., 2001).
Hamidzada and Osuobeni (1999) investigated the agreement between measurements of the intraocular distances by A- and B-scanning modes, and verified significantly different readings between methods when different structures of the eye were evaluated.

In the present research, ocular biometry of the anterior and vitreous chamber depth, lens thickness, and the axial globe length among normal and nondiabetic cataractous eyes of English Coker Spaniels were studied by means of A- and B-modes ultrasonography.

\section{MATERIAL AND METHODS}

Twenty-three English Cocker Spaniels older than eight years were selected for this study. The research was conducted from September 2007 to May 2008 and the study was approved by the Ethics Committee on Animal Experimentation of the Faculdade de Ciências Agrárias e Veterinárias - UNESP (Protocol No. 009462-08), Jaboticabal, SP, Brazil, and followed the ethical norms of the Association for Research in Vision and Ophthalmology (ARVO), National Institute of Health, Publications no. 85-23, revised (NIH..., 1985).

The animals $(\mathrm{n}=23)$ were distributed into two groups, one being formed by dogs with bilateral nondiabetic mature cataracts $(n=16)$, and the other by healthy dogs $(n=7)$ that served as controls. Prior to ultrasonographic (Ultrascan A/B - Alcon ${ }^{\circledR}$ ) evaluation, all subjects underwent a full ophthalmic examination, based on dazzle and pupilary reflexes, Schirmer tear test (Ophthalmos Ltda.), slit lamp biomicroscopy (Kowa Company Ltd.), gonioscopy (Koeppe medium diagnostic lens $18 \mathrm{~mm}-$ Ocular $\left.^{\circledR}\right)$, tonometry (TonoPen XL - Medtronic), binocular indirect ophthalmoscopy (Eyetec S.A.), and fluorescein stainig (Ophthalmos Ltda.).

A- and B-modes ultrasonography was performed bilaterally by different operators, with a $10 \mathrm{MHz}$ broadband compact linear array transducer (Universal Medical Systems Inc.). Prior to the procedure, all dogs received an anesthetic drop containing $0.5 \%$ proximetacaine chloride (Anestalcon - Alcon do Brasil ). Evaluations were made with the probe placed directly on the cornea with $2 \%$ methylcellulose (transmission gel, water soluble contact medium for 
ultrasound) as a coupling gel, and the images were pressed into thermal paper (Mitsubishi K65 HM).

The anterior chamber depth was measured as the distance between echoes from the posterior corneal surface (C1) (corresponding to the Descemet membrane) and the anterior lens surface (L1). The lens thickness was the distance between echoes from L1 and posterior lens surfaces (L2). The vitreous chamber depth was the distance between echoes from L2 and retina (R). The axial globe length was measured from $\mathrm{C} 1$ (corneal surface) to R (Figures 1 and 2).

One way analysis of variance was performed and Tukey was used as a post-hock test to compare measurements between right and left eyes of female and male dogs with cataractous and normal eyes. $\mathrm{P}$ values less than 0.05 were considered significant.
Mean and standard deviation $( \pm$ SD) of biometric readings did not change significantly among cataractous and normal eyes $(\mathrm{P}>0.05)$. The average of axial globe length values for cataractous and normal eyes were $19.909 \pm 1.103 \mathrm{~mm}$ and $19.958 \pm 1.050 \mathrm{~mm}$, respectively. Mean and \pm SD values among right and left eyes in cataractous and noncataractous eyes for the anterior chamber, lens thickness, and vitreous chamber values were: $3.041 \pm 0.828 \mathrm{~mm}$, and $3.373 \pm 1.040 \mathrm{~mm} ; 6.817 \pm 1.117 \mathrm{~mm}$, and $7.062 \pm 0.477 \mathrm{~mm}$; and $10.056 \pm 0.754 \mathrm{~mm}$, and $9.523 \pm 0.70 \mathrm{~mm}$, respectively.

Significant differences in the measured parameters were not seen between right and left eyes, as well as in noncatatractous males and females. Mean \pm SD values for the axial globe length, anterior chamber, lens, and posterior chamber of cataractous and noncataractous right and left eyes are shown in Table 1. Comparative data regarding gender are show in Table 2.

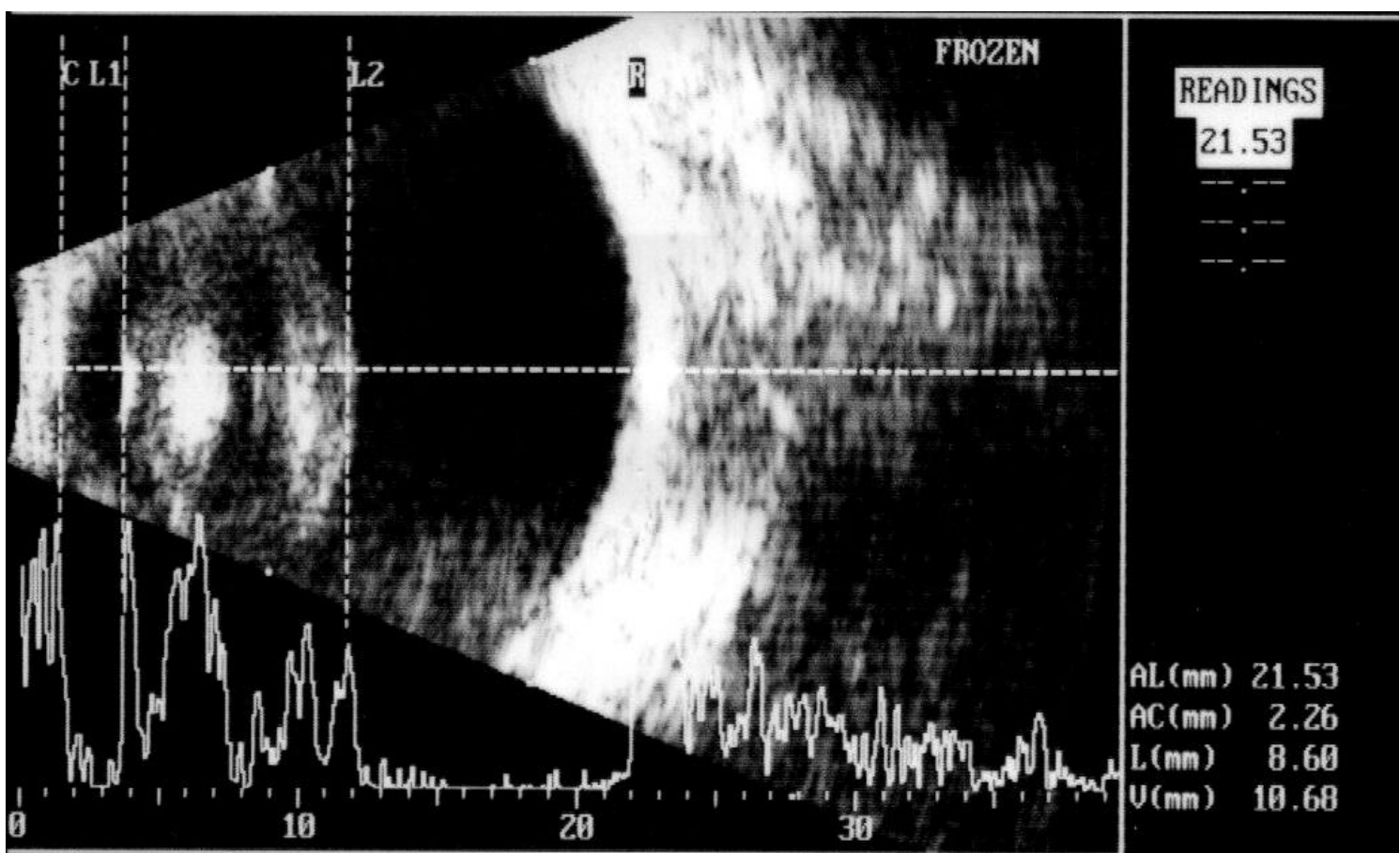

Figure 1. Transcorneal A- and B-modes ultrasonography from a dog with cataract. Note the axial globe length (AL: $21.53 \mathrm{~mm}$, distance between $\mathrm{C}$ and $\mathrm{R}$ ) of the anterior chamber (AC: $2.26 \mathrm{~mm}$, distance between $\mathrm{C}$ and L1), lens (L: $8.60 \mathrm{~mm}$, distance between L1 and L2), and posterior chamber (V: $10.68 \mathrm{~mm}$, distance between $\mathrm{L} 2$ and $\mathrm{R})$.

C: cornea; L1: anterior capsule, L2: posterior capsule, and R: retina. Note the spikes generated by structures more echogenic in the A-mode. 


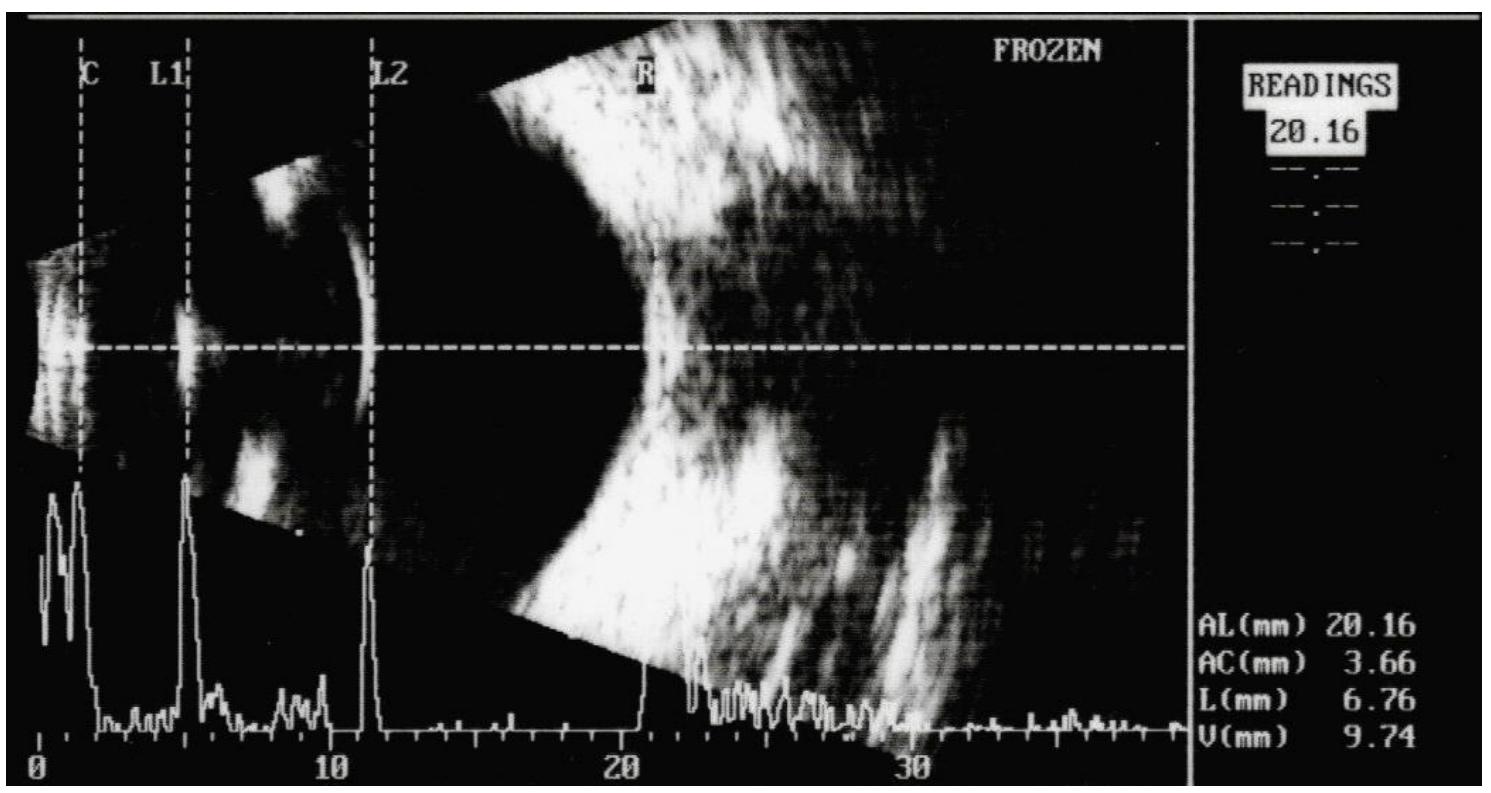

Figure 2. Transcorneal A- and B-modes ultrasonography from a dog with cataract. Note the axial globe length (AL: $20.16 \mathrm{~mm}$, distance between $\mathrm{C}$ and $\mathrm{R}$ ) of the anterior chamber (AC: $3.66 \mathrm{~mm}$, distance between C and L1), lens (L: $6.76 \mathrm{~mm}$, distance between L1 and L2), and posterior chamber (V: 9.74mm, distance between L2 and R).

C: cornea, L1: anterior capsule, L2: posterior capsule, and R: retina. Note that are spikes generated by structures more echogenic in the A-mode.

Table 1. Mean $(\mathrm{mm}) \pm$ standard deviation $(\mathrm{SD})$ of A- and B-modes ultrasonograms measurements of the axial globe length (AL), anterior chamber depth (AC), lens thickness (L), and vitreous chamber (V) between right (RE) and left (LE) eyes of English Cocker Spaniel dogs *

\begin{tabular}{llllll}
\multicolumn{2}{c}{ Group } & \multirow{2}{*}{$\mathrm{N}$} & \multicolumn{4}{c}{ Mean $\pm \mathrm{SD}$} \\
\cline { 3 - 6 } & & $\mathrm{AL}(\mathrm{mm})$ & $\mathrm{AC}(\mathrm{mm})$ & $\mathrm{L}(\mathrm{mm})$ & $\mathrm{V}(\mathrm{mm})$ \\
\hline RE with cataract & 16 & $19.86 \pm 1.04$ & $2.86 \pm 0.90$ & $6.92 \pm 1.02$ & $10.07 \pm 0.77$ \\
LE with cataract & 16 & $19.79 \pm 0.91$ & $2.57 \pm 0.45$ & $7.33 \pm 0.86$ & $9.89 \pm 0.96$ \\
RE control group & 7 & $19.93 \pm 1.22$ & $3.66 \pm 1.46$ & $7.14 \pm 0.35$ & $9.13 \pm 0.82$ \\
LE control group & 7 & $20.34 \pm 0.96$ & $3.32 \pm 0.74$ & $7.19 \pm 0.57$ & $9.83 \pm 0.59$ \\
\hline
\end{tabular}

*Tukey test $(\mathrm{P}>0.05)$.

Table 2. Mean $(\mathrm{mm}) \pm$ standard deviation $(\mathrm{SD})$ of A- and B-modes ultrasonograms measurements of the axial globe length (AL), anterior chamber depth (AC), lens thickness (L), and vitreous chamber (V) between male and female English Cocker Spaniel dogs *

\begin{tabular}{llllll}
\hline \multirow{2}{*}{\multicolumn{1}{c}{ Group }} & \multirow{2}{*}{$\mathrm{N}$} & \multicolumn{4}{c}{ Mean \pm SD } \\
\cline { 3 - 6 } & & $\mathrm{AL}(\mathrm{mm})$ & $\mathrm{AC}(\mathrm{mm})$ & $\mathrm{L}(\mathrm{mm})$ & $\mathrm{V}(\mathrm{mm})$ \\
\hline Cataractous males & 20 & $19.93 \pm 1.16$ & $3.23 \pm 0.63$ & $6.49 \pm 1.08$ & $10,21 \pm 0.77$ \\
Cataractous females & 12 & $19.87 \pm 1.05$ & $2.72 \pm 1.02$ & $7.36 \pm 0.97$ & $9,79 \pm 0.67$ \\
Normal males & 4 & $20.12 \pm 1.26$ & $3.07 \pm 0.37$ & $7.04 \pm 0.61$ & $10,01 \pm 0.38$ \\
Normal females & 10 & $19.87 \pm 1.01$ & $3.52 \pm 1.25$ & $7.07 \pm 0.44$ & $9,27 \pm 0.71$ \\
\hline
\end{tabular}

*Tukey test $(\mathrm{P}>0.05)$.

\section{DISCUSSION}

Animals aged eight years and older were chosen as they are more likely to develop cataract (Williams et al., 2004; Gelatt and MacKay,
2005). Likewise, the English Coker Spaniel was chosen due to the high frequency that such disease is seen in this breed (Gelatt and MacKay, 2005). Although a previous study had shown a higher incidence of cataracts in females of this 
breed (Gelatt and MacKay, 2005), this study overrepresented by males did not show significant differences.

Significant differences in the axial globe length described by Ekesten and Torrång (1995) and by Tuntivanich et al. (2007) were also not observed in this study. However, in the study of Tuntivanich et al. (2007), the axial globe length increased up to 52 weeks, and thereafter such increases were not significant.

Ekesten (1994) showed that A-mode ultrasonographic evaluations in sedated dogs are less amenable to errors in comparison to dogs that were nonsedated during the procedure.

Williams (2004) employed B-mode ultrasonography to compare normal and cataractous lenses of dogs. Lenses with diabetic cataracts were significantly increased in axial thickness compared to lenses in other eyes, although lenses with mature cataracts showed a trend towards increased axial thickness, and immature cataracts demonstrated a trend toward reduced thickness. Similar findings were seen by Fernandes (2008) for the axial lens thickness and anterior chamber depth in diabetic cataractous eyes. Nonetheless, such parameters did not change significantly in eyes presenting with cataracts in different stages. In the present study, it was expected that all dogs with mature or hypermature nondiabetic cataracts had thicker lenses compared to the normal ones.

Boroffka et al. (2006) showed that intra- and interobserver repeatability errors did not contribute to the occurrence of discrepant results when B-mode ultrasound is used as tool for ocular biometry. However, the percentage difference between observations can be high for smaller measurements (Boroffka et al., 2006). In addition, Hamidzada and Osuobeni (1999) verified significant differences between $\mathrm{A}$ - and B-modes ultrasonographic readings when different structures of the eye were evaluated.

\section{CONCLUSION}

The ocular echobiometric readings of the anterior and vitreous chamber, lens and axial globe length do not differ in cataractous and noncataractous English Coker Spaniel dogs older than eight years.

\section{ACKNWOLEDGMENTS}

The authors would like to thank the Fundação de Amparo à Pesquisa do Estado de São Paulo by the grant support and Starky Muller for reading this manuscript.

\section{REFERENCES}

BOROFFKA, S.A.; VOORHOUT, G.; VERBRUGGEN A.M. et al. Intraobserver and interobserver repeatability of ocular biometric measurements obtained by means of B-mode ultrasonography in dogs. Am. J. Vet. Res., v.67, p.1743-1749, 2006.

BRAZITIKOS, P.D.; TSINOPOULOS, I.T.; PAPADOPOULOS, N.T. et al. Ultrasonography classification and phacoemulssification of white senile cataracts. Ophthalmology, v.106, p.21782183, 1999.

COTTRILL, N.B.; BANKS, W.J.; PECHMAN, R.D. Ultrasonic and biometric evaluation of the eye and the orbit of dogs. Am. J. Vet. Res., v.50, p.898-903, 1989.

DAVIDSON, M.G.; NELMS, S.R. The canine lens. In: GELATT, K.N. (Ed). Veterinary ophthalmology. Malvern: Lea \& Febiger, 1999. p.429-460.

EKESTEN, B. Biological variability and measurement error variability in ocular biometry in Samoyed dogs. Acta Vet. Scand., v.35, p.427433, 1994.

EKESTEN, B.; TORRÅNG, I. Age-related changes in ocular distances in normal eyes of Samoyeds. Am. J. Vet. Res., v.56, p.127-133, 1995.

FERNANDES, E. Ultrassonografia na avaliação pré-cirúrgica da lente e do segmento posterior do bulbo de olho de cães com catarata. Correlação entre estádio evolutivo da enfermidade de eventos visibilizáveis em fundo de olho. 2008. 54f. Dissertação (Mestrado) Faculdade de Ciências Agrárias e Veterinárias, Universidade Estadual Paulista, Jaboticabal.

GELATT, K.N.; MACKAY, E.O. Prevalence of primary breed-related cataracts in the dog in North America. Vet. Ophthalmol., v.8, p.101$111,2005$. 
GONZALES, E.M.; RODRIGUEZ, A.; GARCIA, I. Review of ocular ultrasonography. Vet. Radiol. Ultrasound., v.42, p.485-495, 2001.

HAMIDZADA, W.A.; OSUOBENI, E.P. Agreement between A-mode and B-mode ultrasonography in the measurement of ocular distances. Vet. Radiol. Ultrasound., v.40, p.502507, 1999.

MARTINS, B.C.; LIMA, F.S.; LAUS, J.L. Simultaneous mode A and mode B echobiometry of senile cataractous eyes in dogs. Arq. Bras. Med. Vet. Zootec., v.62, p.42-46, 2010.

PETERSEN-JONES, S.M. Clinical and molecular genetics. In: GELATT, K.N. (Ed). Veterinary ophthalmology. Malvern: Lea \& Febiger, 1999. p.219-238.
TUNTIVANICH, N.; PETERSEN-JONES, S.M.; STEIBEL, J.P. et al. Postnatal development of canine axial globe length measured by B-scan ultrasonography. Vet. Ophthalmol., v.10, p.2-5, 2007.

van der WOERDT, A.; WILKIE, D.A.; MYER, C.W. Ultrasonographic abnormalities in the eyes of dogs with cataracts:147 cases (1986-1992). J. Am. Vet. Med. Assoc., v.203, p.838-841, 1993.

WILLIAMS, D.L.; HEATH, M.F.; WALLIS, C. Prevalence of canine cataract: preliminary results of a cross-sectional study. Vet. Ophthalmol., v.7, p.29-35, 2004.

WILLIAMS, D.L. Lens morphometry determined by B-mode ultrasonography of the normal and cataractous canine lens. Vet. Ophthalmol., v.7, p.91-95, 2004. 